Ewa Gumul D

Uniwersytet Śląski

ewa.gumul@us.edu.pl

\title{
O metodzie badawczej zapożyczonej z psychologii, czyli jak zaprojektować i przeprowadzić badanie za pomocą metody protokołów retrospektywnych w thumaczeniu symultanicznym
}

Protokoły retrospektywne, od kilku dekad stosowane z powodzeniem w badaniach przekładoznawczych, to metoda badawcza zapożyczona z psychologii. Polega ona na przywołaniu z pamięci i zwerbalizowaniu świadomych procesów kognitywnych, które miały miejsce w trakcie przekładu. Jak sama nazwa wskazuje, retrospekcja następuje już po ukończeniu zadania tłumaczenia.

Metoda ta po raz pierwszy została opisana w sposób systematyczny w pracach psychologów Ericssona i Simona [1980, 1984]. Wielu przekładoznawców stosujących tę metodę opiera się, przynajmniej do pewnego stopnia, właśnie na tych pracach [np. Ivanova 1999, 2000; Vik-Tuovinen 2002; Bartłomiejczyk 2006; Englund Dimitrova i Tiselius 2009, 2014]. Narzędzie to zyskało także znaczną popularność w glottodydaktyce i niektórzy badacze przekładu wzorują się na pracach z tej dziedziny. Przykładem są prace Russell i Winston [2014] oraz Díaz Galaz [2018], w których autorki opierają się na założeniach metodologicznych 
zaproponowanych przez Gass i Mackey [2000/2009] na potrzeby badań nad przyswajaniem języków obcych.

Celem artykułu jest omówienie poszczególnych etapów badania przeprowadzonego $\mathrm{z}$ użyciem metody retrospekcji $\mathrm{w}$ thumaczeniu symultanicznym. Potrzeba taka wynika $\mathrm{z}$ braku przejrzystości procedur badawczych tego typu w badaniach translatorycznych, co znacznie utrudnia porównywanie wyników. Materiał egzemplifikacyjny pochodzi z badań własnych autorki [Gumul 2017].

\section{Projektowanie badania}

\subsection{Triangulacja z innymi metodami badawczymi}

Projektując badanie z użyciem metody protokołów retrospektywnych $\mathrm{w}$ translatoryce, należy przede wszystkim pamiętać, że rzadko kiedy jest ona wykorzystywana jako jedyne narzędzie badawcze. W większości przypadków konieczna jest triangulacja z innymi metodami badawczymi, co podkreśla wielu badaczy stosujących te metodę [np. Hild 2007, 2015; Tiselius i Jenset 2011]. Jednak w przeciwieństwie do przekładu pisemnego, w którym badacz ma do dyspozycji, oprócz tradycyjnej analizy produktu, badanie okulografem, śledzenie ruchów na klawiaturze (keylogging) oraz jednoczesną werbalizację podejmowanych decyzji w formie protokołów głośnego myślenia (ang. TAPS), w przypadku tłumaczenia ustnego możliwości są bardzo ograniczone ze względu na jego specyfikę. Możliwa jest jedynie dodatkowa analiza produktu przekładu (porównanie tekstu wyjściowego z docelowym) oraz włączenie do badania kwestionariuszy ankiet i dziennika prowadzonego przez badanych thumaczy ${ }^{1}$, choć dwie ostatnie metody również należy uznać za pewną formę retrospekcji. Konieczność triangulacji wynika $\mathrm{z}$ dwóch powodów.

Po pierwsze, do analizy wielu zjawisk zachodzących w procesie przekładu same relacje tłumaczy nie są wystarczające. Badanie większości zjawisk wymaga analizy produktu przekładu. Często nieodzowne jest prześledzenie, w jaki sposób opisywany w protokole retrospektywnym problem czy rozwiązanie manifestuje się $\mathrm{w}$ tekście oraz jakie

\footnotetext{
1 Mowa tu o klasycznej formie thumaczenia symultanicznego, będącego przedmiotem analizy w niniejszym artykule. W wielu innych formach thumaczenia ustnego (np. tłumaczenie symultaniczne $\mathrm{z}$ tekstem lub prezentacją, tłumaczenie a vista, tłumaczenie konsekutywne) możliwe jest połączenie retrospekcji z badaniem za pomocą okulografu.
} 
są zależności pomiędzy relacjonowanym segmentem a innymi częściami tekstu. Wyjątek stanowią jedynie badania, których celem jest analiza percepcji zastosowanych przez tłumaczy rozwiązań. Przykładem jest praca Bartłomiejczyk [2007b] na temat samooceny jakości przekładu oraz praca Gumul [2012] przestawiająca, w jaki sposób studenci uczący się tłumaczenia symultanicznego postrzegają ograniczenia tej formy przekładu. Po drugie, należy pamiętać, że jest to metoda subiektywna. Badacz polega jedynie na relacjach respondentów, które z różnych powodów mogą nie odzwierciedlać realnego procesu tłumaczenia [zob. Gumul 2019].

Poniższy przykład (1) przedstawia część materiału zebranego na potrzeby badania łączącego analizę produktu przekładu (poprzez manualne porównanie tekstu wyjściowego $\mathrm{z}$ docelowym) $\mathrm{z}$ analizą protokołu retrospektywnego [Gumul 2017]. W tym wypadku triangulacja metod badawczych była konieczna ze względu na cel badania, jak i specyfikę analizowanego zjawiska. Jako że jednym z celów badania była analiza strategiczności, czyli celowego i świadomego zastosowania eksplicytacji, zestawienie przypadków tej operacji tekstowej relacjonowanych przez thumaczy podczas retrospekcji ze wszystkimi przypadkami zidentyfikowanymi w tekście docelowym pozwoliło na określenie, w jakim stopniu eksplicytacja jest świadomym działaniem thumacza. Materiał badawczy obejmuje transkrypcję tekstu wyjściowego, transkrypcję tekstu docelowego oraz zapis protokołu retrospektywnego podzielonego na mniejsze segmenty - komentarze odnoszące się do danego fragmentu tekstu docelowego, czego przykładem jest zaprezentowany poniżej fragment protokołu (od RC16 do RC23):

\begin{tabular}{|c|c|c|}
\hline Tekst wyjściowy: & Tekst docelowy: & $\begin{array}{l}\text { Komentarze } \\
\text { retrospektywne: }\end{array}$ \\
\hline $\begin{array}{l}\text { ST (T3): } \\
\text { in the United States the } \\
\text { law and all the codes sug- } \\
\text { gest that a physician can } \\
\text { refuse to do something to } \\
\text { which they feel is morally } \\
\text { against their wishes / }\end{array}$ & $\begin{array}{l}\text { TT (P73): } \\
\text { w Stanach Zjednoczonych } \\
\text { prawo i wszystkie kodeksy } \\
\text { prawne sugerują że lekarz } \\
\text { może odmówić wykonania } \\
\text { pewnych czynności które } \\
\text { uważa za eee by za czynności } \\
\text { które przeczą jego moralno- } \\
\text { ści*RC16 / }\end{array}$ & \\
\hline
\end{tabular}

2 Symbole użyte w kodowaniu materiału badawczego zostaną wyjaśnione w sekcji 1.5. 


\begin{tabular}{|c|c|c|}
\hline $\begin{array}{l}\text { nk of the best inter- } \\
\text { f the patient / and } \\
\text { if a physician does } \\
\text { ant to provide such } \\
\text { it is their obligation } \\
\text { st to refer the patient } \\
\text { mebody else or tell } \\
\text { about options that } \\
\text { vailable rather than } \\
\text { aying no / there was } \\
\text { ent article published } \\
\text { Jew England Journal } \\
\text { edicine that looked at } \\
\text { two thousand physi- } \\
\text { in the United States } \\
\text { how they would re- } \\
\text { d to certain questions } \\
\text { what to do if they } \\
\text { asked by a patient / } \\
\text { ay give a prescrip- } \\
\text { or a morning-after } \\
\text { or to provide a help } \\
\text { lying person / those } \\
\text { of questions / most } \\
\text { ot all believed it } \\
\text { ations } \\
\text { describal or moral to at } \\
\text { tion to the patient } \\
\text { were obligated to } \\
\text { hey were obligated to } \\
\text { to another physician } \\
\text { you'll notice by the } \\
\text { ers here that maybe } \\
\text { of of these } \\
\text { ansicians }\end{array}$ & $\begin{array}{l}\text { usimy pamiętać } \\
\text { ujemy eee } \\
\text { ie pacjenta / } \\
\text { ak najlepiej } \\
\text { lekarz nie chce } \\
\text { pewnych czyn- } \\
\text { ych z udziele- } \\
\text { / to ee ma on } \\
\text { zynajmniej eee } \\
\text { słać pacjenta } \\
\text { stki* RC17 } \\
\text { eć poinformo- } \\
\text { ch możliwych } \\
\text { krótko mówiąc } \\
\text { mu pomocy / } \\
\text { ykuł opubliko- } \\
\text { zynie medycz- } \\
\text { ee wziął pod } \\
\text { lwóch tysięcy } \\
\text { padał jak będą } \\
\text { liektóre pytania } \\
\text { ee na takie } \\
\text { w których } \\
\text { ch o wypisanie } \\
\text { ieś niedozwo- } \\
\text { l9 albo na } \\
\text { szoś eutanazję- } \\
\text { nają obowaraiązentáw } \\
\text { ch moralnych } \\
\text { acjentowi // } \\
\text { igowani eee } \\
\text { a osobę do } \\
\text { / }\end{array}$ & $\begin{array}{l}\text { ponieważ było } \\
\text { te w oryginale } \\
\text { o ogólnie, czyli } \\
\text { nebody, a ja zro- } \\
\text { z tego przekazać } \\
\text { nej jednostki, } \\
\text { na myśli już } \\
\text { zpital lub jakąś } \\
\text { ę. } \\
\text { 3: Uogólniłem } \\
\text { nie wprowadzać } \\
\text { lś niepotrzeb- } \\
\text { złych nazw do } \\
\text { y własnej tego } \\
\text { zynu, po prostu } \\
\text { rdziłem, że jest } \\
\text { gazyn medyczny, } \\
\text { ostatnio opubli- } \\
\text { łartykuł. } \\
\text { : Uogólniłem, } \\
\text { nie chciałem } \\
\text { yć czegoś, co być } \\
\text { nie byłoby do- } \\
\text { odpowiednikiem } \\
\text { my antykoncep- } \\
\text { więc stwierdziłem } \\
\text { ie, że są to leki } \\
\text { zwolone. }\end{array}$ \\
\hline
\end{tabular}




\begin{tabular}{|c|c|c|}
\hline $\begin{array}{l}\text { / in the United Sates this } \\
\text { would mean that perhaps } \\
\text { forty million people were } \\
\text { treated by physicians } \\
\text { who felt no obligation to } \\
\text { explain other options or to } \\
\text { refer them to another phy- } \\
\text { sician / if the question was } \\
\text { about the procedure that } \\
\text { was morally not right for } \\
\text { the physician / ok let me } \\
\text { skip this / there are two } \\
\text { other issues very briefly } \\
\text { / if a physician is putting } \\
\text { a patient at risk because } \\
\text { they have an infection } \\
\text { / they are obligated to } \\
\text { protect the patient by not } \\
\text { performing procedures / } \\
\text { let's say they have hepa- } \\
\text { titis and they shouldn't be } \\
\text { operating on patients / so } \\
\text { what do we need to do? / } \\
\text { we really need as physi- } \\
\text { cians to ensure that people } \\
\text { who are in need get care } \\
\text { / even in an environment } \\
\text { where institutions may } \\
\text { not necessarily be able } \\
\text { to deliver that care / we } \\
\text { need to look at our current } \\
\text { codes to decide if they are } \\
\text { ment towards not just } \\
\text { peophysician taking care of } \\
\text { that people can get care / } \\
\text { and policies and laws / we } \\
\text { need to think of new mod- } \\
\text { els of care / in the United } \\
\text { theams / }\end{array}$ & $\begin{array}{l}\text { ale po ee danych liczbowych } \\
\text { widać że jedna trzecia leka- } \\
\text { rzy eee nie czuła nie poczu- } \\
\text { wała się do żadnego z tych } \\
\text { obowiązków / w Stanach } \\
\text { Zjednoczonych oznacza- } \\
\text { łoby to być może że około } \\
\text { czterdziestu milionów ludzi } \\
\text { jest leczonych przez lekarzy } \\
\text { którzy nie czuli żadnego } \\
\text { obowiązku ee wyjaśnienia } \\
\text { i poinformowania o innych } \\
\text { opcjach lub skierowania } \\
\text { do innego lekarza // gdyby } \\
\text { zadać pytanie dotyczące } \\
\text { czynności eee / które nie } \\
\text { były niemoralne dla danego } \\
\text { lekarza // eee dobra pomińmy } \\
\text { to / e skupmy się na dwóch } \\
\text { innych aspektach bardzo } \\
\text { krótko / eee jeżeli / e lekarz } \\
\text { eee zagraża pacjentowi to ma } \\
\text { on obowiązek zaniechania } \\
\text { wykonywania czynności / na } \\
\text { przykład jeżeli pacjent ee je- } \\
\text { żeli pacjent ma żżż zakażenia } \\
\text { wątroby zapalenia wątroby } \\
\text { to pacjent to lekarz nie powi- } \\
\text { nien wykonywać operacji na } \\
\text { takim pacjencie / powinni- } \\
\text { śmy mieć eee postanowione } \\
\text { że ludzie którzy potrzebują } \\
\text { którzy potrzebują pomocy } \\
\text { powinni być nią otoczeni // } \\
\text { musimy spojrzeć na kodeksy } \\
\text { obecne aby zdecydować eee } \\
\text { czy ee są one wystarczająco } \\
\text { eee solidne }\end{array}$ & $\begin{array}{l}\text { RC20: Natomiast tutaj } \\
\text { nieco chyba nadinter- } \\
\text { pretowałem, ponieważ } \\
\text { tutaj jest o udzielaniu } \\
\text { pomocy osobie umie- } \\
\text { rającej, natomiast ja tę } \\
\text { pomoc potraktowałem } \\
\text { jako eutanazję. } \\
\text { RC21: Ze względu na } \\
\text { to, że zdanie było nieco } \\
\text { niegramatyczne i po } \\
\text { stwierdzeniu solidne } \\
\text { urwało mi się trochę } \\
\text { i nie wiedziałem, } \\
\text { o czym dokładnie jest } \\
\text { mowa, to stwierdziłem, } \\
\text { że zakończę na tym to } \\
\text { zdanie żeby nie wpro- } \\
\text { wadzać nowej myśli } \\
\text { i nie kończyć jej. } \\
\text { RC22: Celowo po- } \\
\text { minąłem całe pytanie } \\
\text { retoryczne, o którym } \\
\text { tak naprawdę nie } \\
\text { wiedziałem, do czego } \\
\text { się odnosi i jak by to } \\
\text { ująć w języku polskim. } \\
\text { Dlatego stwierdziłem, } \\
\text { że zgrabniej będzie } \\
\text { pominąc to i rozpocząć } \\
\text { tłumaczenie od następ- } \\
\text { nej myśli, która i tak do } \\
\text { tego nawiązuje. } \\
\text { RC23: Zastosowałem } \\
\text { omission ponieważ nie } \\
\text { usłyszałem fragmentu } \\
\text { i nie zrozumiałem } \\
\text { pierwszej części } \\
\text { wypowiedzi. }\end{array}$ \\
\hline
\end{tabular}




\begin{tabular}{|c|c|}
\hline $\begin{array}{l}\text { what are the ethical } \\
\text { implication under those } \\
\text { circumstances? / there } \\
\text { is the issue of restricting } \\
\text { resident's work hours / } \\
\text { they are not encouraged or } \\
\text { not allowed to stay longer } \\
\text { than the hours they are al- } \\
\text { located / what happens if } \\
\text { the person is sick and they } \\
\text { should stay / they some- } \\
\text { how have to transfer care } \\
\text { to another / this is a whole } \\
\text { new way of taking care } \\
\text { of patients that none of } \\
\text { us grew up with / but is } \\
\text { going to be the reality of } \\
\text { the future and we need to } \\
\text { think of new ethical ways } \\
\text { to ensure that patients get } \\
\text { the appropriate care / }\end{array}$ & $\begin{array}{l}\text { *RC21 // e musimy eee } \\
\text { stworzyć nowe modele } \\
\text { e udzielania pomocy w Sta- } \\
\text { nach Zjednoczonych eee ist- } \\
\text { nieje obecnie ruch eee który } \\
\text { nie tylko podkreśla / eee że } \\
\text { jeden lekarz bierze odpowie- } \\
\text { dzialność za pacjenta lecz } \\
\text { bierze za niego odpowie- } \\
\text { dzialność cała grupa*RC22 } \\
\text { // istnieje także kwestia / eee } \\
\text { ograniczenia e godzin które } \\
\text { lekarze powinni wykonywać } \\
\text { w pracy // eee / lekarzy nie } \\
\text { zachęca się do pozostawania } \\
\text { w pracy dłużej niż jest to wy- } \\
\text { znaczone w ich grafiku / co } \\
\text { natomiast eee dzieje się jeżeli } \\
\text { pacjent jest chory i lekarz } \\
\text { taki powinien z nim zostać } \\
\text { / eee / muszą oni przekazać } \\
\text { obowiązek opieki nad danym } \\
\text { pacjentem do innego lekarza } \\
\text { //*RC23 jest to jednak rze- } \\
\text { czywistość i musimy stwo- } \\
\text { rzyć nowe metody etyczne } \\
\text { aby zapewnić że pacjenci są } \\
\text { otoczeni odpowiednią opieką } \\
\text { zdrowotna }\end{array}$ \\
\hline
\end{tabular}

\subsection{Dobór uczestników badania}

Kolejnym istotnym czynnikiem w projektowaniu badania jest dobór uczestników. Ze względu na swój charakter badania z wykorzystaniem retrospekcji są na ogół przeprowadzane w warunkach laboratoryjnych, jako że przeprowadzenie sesji retrospektywnej podczas realnej konferencji lub innego zlecenia jest niemożliwe. Istnieją co prawda prace, w których badani tłumacze odnoszą się do przekładów wykonanych na potrzeby realnych zleceń [np. Vik-Tuovinen 2002]. Wymuszają one jednak znacznie opóźnioną retrospekcję, co niestety wpływa negatywnie na wiarygodność uzyskanych w ten sposób werbalizacji [zob. Gumul 2019]. 
Badania przeprowadzone w warunkach laboratoryjnych dają możliwość kontrolowania pewnych zmiennych dobieranych w zależności od celu badania (np. tempa wypowiedzi lub cech leksykalno-syntaktycznych tekstu wyjściowego itp.). Dlatego też mogą przybierać formę eksperymentów lub quasi-eksperymentów. Z tym wiąże się kolejny aspekt dotyczący doboru uczestników. Warunkiem eksperymentu jest losowy dobór uczestników i przypisanie ich do grupy eksperymentalnej i kontrolnej zgodnie z tą zasadą [Creswell 2013]. Badania z wykorzystaniem metody retrospekcji z dziedziny psychologii na ogół spełniają te warunki. Jednak ze względu na specyfikę badań translatorycznych większość badań z tej dziedziny przyjmuje raczej formę quasi-eksperymentów [np. Englund Dimitrova i Tiselius 2009, 2014; Tang 2018], jako że podział uwzględnia naturalnie powstałe grupy. Przykładowo w badaniach Englund Dimitrowej i Tiselus porównano tłumaczy pisemnych i ustnych, a w pracy Tang - studentów z zawodowymi tłumaczami, co w obu przypadkach stanowiło kryterium przydziału uczestników do danej grupy. Dla porównania losowe przyporządkowanie badanych osób do grup eksperymentalnych było możliwe w badaniu Gumul [2020], w którym przydzielono uczestników do grup za pomocą tablicy liczb losowych (wykorzystano tablice z Brzezińskiego [2008: 247]; zob. także Brzeziński i Stachowski [1984]). W przypadku tego eksperymentu było to możliwe, ponieważ zmienną niezależną różnicującą dwie grupy badawcze był rodzaj bodźca stymulującego pamięć podczas retrospekcji.

Porównując badania $\mathrm{z}$ dziedziny psychologii z pracami przekładoznawczymi, warto zaznaczyć, że w translatoryce wiele badań, które nie są badaniami obserwacyjnymi przeprowadzonymi w warunkach naturalnych, często określa się mianem badań eksperymentalnych [Liu 2011, 2015], choć z punktu widzenia metodologii badań psychologicznych w większości przypadków nie spełniają one warunków nawet quasi-eksperymentów i należałoby raczej mówić o preeksperymentalnym schemacie badawczym [np. Bartłomiejczyk 2006; Gumul 2012; Shamy i de Pedro Ricoy 2017] lub czasami wręcz o zebraniu materiału w warunkach laboratoryjnych. Taki stan rzeczy wynika przede wszystkim ze specyfiki badań translatorycznych, a zwłaszcza badań tak czasochłonnych jak te z wykorzystaniem protokołów retrospektywnych. Jak podkreśla Liu [2015], w praktyce dostępność tłumaczy gotowych wziąć udział w badaniach jest 
bardzo ograniczona. Wielkość próby uniemożliwia zatem losowy dobór uczestników przy jednoczesnej kontroli określonych zmiennych.

Warunki laboratoryjne sprawiają, że uczestnikami badania mogą być zarówno zawodowi praktykujący thumacze, jak i studenci thumaczenia na właściwie każdym etapie edukacji. Oczywiście w przypadku tych ostatnich trudno oczekiwać możliwości ekstrapolacji wyników na całą populację tłumaczy. Badania translatoryczne często bywają krytykowane ze względu na dobór studentów thumaczenia jako uczestników [ibidem]. Jednak badania z udziałem studentów niekoniecznie muszą być z założenia niepoprawne metodologicznie. Jeśli celem jest zbadanie określonego zjawiska na pewnym etapie szkolenia [np. Gumul 2017; Shamy i de Pedro Ricoy 2017], poprawność metodologiczna zostaje zachowana. Przykładowo, celem opisywanego w artykule badania własnego autorki [Gumul 2017] była analiza zachowań eksplicytacyjnych u studentów na końcowym etapie szkolenia, przy założeniu, że zachowania te mogą znacznie różnić się od tych, które można by było zaobserwować u zawodowych tłumaczy. Dobór uczestników badania został sprecyzowany już w samym podtytule pracy: ,A study into explicitating behaviour of trainee interpreters" i wnioski dotyczą tylko i wyłącznie populacji studentów thumaczenia.

Jak podkreślają Saldanha i O'Brien [2013: 118], udział studentów może wiązać się z problemami natury etycznej. Dzieje się tak w przypadku gdy badacz jest jednocześnie wykładowcą prowadzącym zajęcia $\mathrm{z}$ badaną grupą studentów. W takiej sytuacji studenci mogą czuć się zobligowani do wzięcia udziału w badaniu, co oprócz kwestii etycznych może również wpłynąć na uzyskane wyniki. Chęć pomocy czy przypodobania się wykładowcy może np. wpłynąć na treść werbalizacji w protokołach retrospektywnych, jako że studenci są świadomi oczekiwań prowadzącego z nimi zajęcia wykładowcy jeśli chodzi o kryteria oceny thumaczenia. Mogą też obawiać się o ocenę końcową z przedmiotu, choć samo badanie nie podlega ocenie. Istnieje zatem ryzyko, że tłumacząc tekst i relacjonując swoje problemy oraz podjęte decyzje podczas sesji retrospektywnej na potrzeby badań nauczyciela, studenci mogą opisywać proces zgodnie z tym, jak chcieliby, by był widziany, a nie jaki w rzeczywistości był. Aby uniknąc tego rodzaju problemów i potencjalnego zafałszowania wyników, do badania lepiej zaprosić studentów, z którymi zajęcia prowadzą inni wykładowcy, lub studentów z innej uczelni, czy też, jak w przypadku 
badania Shamy i de Pedroy Ricoy [2017] z Uniwersyteu Heriot-Watt, zaplanować termin badania po egzaminach końcowych.

W zależności od celu badania często zasadne wydaje się także zróżnicowanie uczestników pod względem dotychczasowego szkolenia. Jeśli uczestnikami badania są profesjonalni tłumacze, takie zróżnicowanie występuje naturalnie. Profil każdego z badanych różni się znacznie, jeśli chodzi zarówno o przebieg kariery zawodowej, jak i ukończone studia, szkolenia czy staże. Inaczej jest, gdy do badania zapraszamy studentów, którzy na ogół stanowią bardzo jednorodną grupę pod względem wcześniejszych zajęć z tłumaczenia. Może to być zaletą, jeśli jednorodny przebieg edukacji tłumaczeniowej jest zmienną, którą chcemy kontrolować, lub istotną wadą, jeśli ten aspekt uznamy za zmienną zakłócającą. $\mathrm{Z}$ tego względu $\mathrm{w}$ opisywanym w niniejszym artykule badaniu [Gumul 2017] uczestniczyli studenci z 3 różnych uczelni (z Uniwersytetu Śląskiego, Uniwersytetu Gdańskiego oraz z Wyższej Szkoły Lingwistycznej w Częstochowie), z którymi zajęcia prowadziło 7 różnych wykładowców. Rozwiązanie takie było konieczne, aby uniknąc wpływu określonego modelu szkolenia na rodzaj i treść werbalizacji podczas retrospekcji, co pozwoliło w większym stopniu na ekstrapolację wyników na populację studentów specjalności thumaczeniowych w kombinacji językowej polski-angielski. Podobne rozwiązanie zastosowały Shamy i de Pedro Ricoy [2017], w których badaniu również uczestniczyli studenci z 3 różnych uniwersytetów brytyjskich. Takie zróżnicowanie uczestników nie zawsze jest oczywiście konieczne i zależy w dużej mierze od celu badania.

Planując badania z wykorzystaniem metody retrospekcji, warto zwrócić uwagę na jeszcze jeden czynnik przy doborze uczestników. $Z$ dotychczas przeprowadzonych badań na temat procesu przekładu wynika, że u thumaczy wraz z nabytym doświadczeniem zawodowym można zaobserwować większy stopnień zautomatyzowania strategii [Bartłomiejczyk 2006]. Można się zatem spodziewać, że werbalizacje profesjonalnych tłumaczy, u których część procesów jest już w pełni zautomatyzowana poprzez długoletnią praktykę, będą mniej obfite niż w przypadku studentów thumaczenia, bardziej świadomie poszukujących rozwiązania napotkanych problemów, z którymi niejednokrotnie konfrontują się po raz pierwszy [zob. Gumul 2019].

Projektując badanie, należy także pamiętać o tym, by chronić tożsamość uczestników badania, zwłaszcza na etapie publikacji wyników i cytowania wypowiedzi - niejednokrotnie bardzo osobistych $-\mathrm{z}$ sesji 
retrospektywnych. Jedną z metod jest oznaczanie poszczególnych uczestników symbolami. Przykładowo w badaniu własnym autorki każdy ze 120 uczestników otrzymał numer poprzedzony literą $\mathrm{P}$ (od słowa participant): od P01 do P120 [Gumul 2017]. Podobne oznaczenia zastosowała również Díaz Galaz [2018]. Niektórzy badacze posługują się także wymyślonymi imionami [Ferreira 2014; Englund Dimitrova i Tiselius 2009].

Dobrą praktyką jest również uzyskanie pisemnej zgody uczestników badania oraz poinformowanie ich, że mogą zrezygnować z badania na każdym jego etapie [Saldanha i O'Brien 2013: 118; zob. także Gumul 2020]. W pewnych przypadkach zalecana jest także zgoda komisji etycznej na badania. Narodowe Centrum Nauki rekomenduje uzyskanie zgody takiej komisji w przypadku badań z udziałem studentów w sytuacji, ,gdy badanie jest prowadzone $\mathrm{w}$ ramach zajęć lub w bezpośrednim związku z zajęciami"’3. Pozwala to uniknąć sytuacji, w których zachodzi obawa, że zgoda na udział w badaniu może nie być w pełni dobrowolna.

\subsection{Instrukcje i przygotowanie badanych do zadania}

Istotnym elementem procedury badawczej jest przygotowanie uczestników do sesji retrospektywnej. Ten etap wymaga opracowania szczegółowego protokołu działania z wyszczególnieniem czynności w taki sposób, aby móc precyzyjnie powtórzyć tę samą procedurę w każdej badanej grupie (czy też u każdego tłumacza, w zależności od warunków, w jakich odbywa się badanie). Przykład takiego szczegółowego protokołu znajdziemy w pracy Gass i Mackey [2000/2009: 119-121], w którym zostały opisane wszystkie czynności, jakie powinna wykonać osoba przeprowadzająca badanie, jak również tekst instrukcji, który należy odczytać badanym. Taki stopień uszczegółowienia protokołu działania jest konieczny, jeśli badanie w różnych grupach przeprowadza więcej niż jeden badacz. Odtworzenie tego samego schematu działania jest niezwykle istotne w tej metodzie, ponieważ zarówno sposób, jak i treść podanych instrukcji ma bezpośredni wpływ na uzyskane raporty werbalne.

W badaniu opisanym w niniejszym artykule [Gumul 2017] biorący w nim udział tłumacze otrzymali krótki słowny instruktaż zawierający także informacje na temat tekstu wyjściowego przed przystąpieniem do tłumaczenia (przykład 2 poniżej) i bardziej szczegółowe instrukcje

\footnotetext{
3 https://www.ncn.gov.pl/sites/default/files/pliki/2016_zalecenia_Rady_NCN_ dot_etyki_badan.pdf.
} 
dotyczące formy i treści protokołów retrospektywnych po zakończonym tłumaczeniu, bezpośrednio przed rozpoczęciem sesji retrospektywnej (przykład 3). Instrukcje te odczytano badanym, a następnie rozdano im wydrukowany tekst instrukcji po to, aby w razie wątpliwości każdy z uczestników mógł w każdej chwili upewnić się co do zasad zadania:

Tekst, który mają Państwo przetłumaczyć, to referat zatytułowany „Can a physician refuse to help a patient? American perspective”, wygłoszony przez Virginię Hood podczas sympozjum satelitarnego „Dylematy etyczne w praktyce lekarskiej - czy lekarz może odmówić pacjentowi pomocy?", zorganizowanego w ramach VII Krajowej Konferencji Szkoleniowej Towarzystwa Internistów Polskich 24 kwietnia 2008 w Warszawie 4 . Tekst ma około 19 minut. Po skończonym thumaczeniu poproszę Państwa o przesłuchanie swojego thumaczenia i skomentowanie go. Szczegółowe instrukcje otrzymają Państwo po zakończeniu tłumaczenia.

Za chwilę wysłuchają Państwo swoich thumaczeń. Proszę o komentarze dotyczące wszystkich świadomie podjętych decyzji w trakcie thumaczenia. Komentarze NIE powinny dotyczyć jakości tłumaczenia, a wyłącznie podjętych decyzji i powodów podjęcia takich decyzji. Ilekroć będą Państwo chcieli skomentować swoje thumaczenie, proszę zatrzymać plik z thumaczeniem i wygłosić komentarz. Proszę oznaczyć komentowany fragment tekstu w tabeli, zapisując dwa lub trzy ostatnie słowa (aby można było ustalić, czego dotyczy komentarz). Nie ma znaczenia język, w jakim będą Państwo robić komentarze. Może to być polski, angielski lub mieszanka obu języków. Proszę nie przejmować się formą komentarzy i ich poprawnością składniową. Powinny to być spontaniczne komentarze. Nie ma limitu ilości komentarzy ani ich długości. Proszę mówić tylko o świadomie podjętych decyzjach, czyli tylko o tym, o czym myśleli Państwo podczas tłumaczenia. Proszę nie wymyślać komentarzy po fakcie na podstawie nagrania własnego tłumaczenia.

Większość badaczy ogranicza się do wyjaśnienia, na czym będzie polegało zadanie, i podania instrukcji jak w opisie powyżej.

$4 \quad$ W zależności od badanej grupy thumaczy część instrukcji dotycząca tekstu wyjściowego ulegała zmianie. W badaniu użyto w sumie 3 zestawów tekstów (na każdy zestaw składał się 1 tekst w języku polskim i $1 \mathrm{w}$ języku angielskim), z których każdy został przetłumaczony przez 40 tłumaczy. 
Jednak w badaniach z dziedziny psychologii i glottodydaktyki poruszany jest także temat wcześniejszego szkolenia badanych. Gass i Mackey [2000/2009] podają przykłady pokazywania badanym nagrań wideo sesji retrospektywnych lub transkrypcji z innego badania. Szkolenie może też obejmować ćwiczenia z retrospekcji na innym materiale. Według Ericssona i Simona [1993] szkolenie badanych nie ma negatywnego wpływu na wiarygodność raportów werbalnych, a wręcz może sprawić, że będą one bardziej kompletne. Jednak nie wszyscy badacze są co do tego zgodni. Gass i Mackey [2000/2009: 37] wskazują, że taka praktyka może wpłynąć na uzyskane w badaniu protokoły retrospektywne, jako że badani mogą kopiować zaobserwowane u innych zachowania, przez co ich raporty będą mniej autentyczne. Badaczki zalecają badania pilotażowe, aby zweryfikować wpływ uprzedniego szkolenia na uzyskane raporty werbalne, i ograniczenie takiego szkolenia do minimum, aby zminimalizować jego wpływ na werbalizacje badanych.

\subsection{Wybór bodźca stymulującego pamięć}

Opóźnienie, jakie w odróżnieniu od protokołów głośnego myślenia narzuca metoda protokołów retrospektywnych, sprawia, że w badaniu przeprowadzonym za pomocą tego narzędzia konieczne jest użycie bodźca stymulującego pamięć badanych osób [zob. w całości poświęcony temu zagadnieniu artykuł Gumul 2020]. Oczywiście, jak podkreślają Gass i Mackey [2000/2009], retrospekcja bez użycia bodźca jest również możliwa, jednak ograniczenia pamięci sprawiają, że raporty mogą być bardziej skąpe, a wspomnienie zapamiętanych procesów mocno zniekształcone. Zwłaszcza w badaniach translatorycznych, gdzie ze względu na specyfikę tej formy aktywności czas trwania zadania jest najczęściej relatywnie długi (od kilku do kilkunastu minut) ${ }^{5}$. Najczęściej stosowane bodźce w badaniach przekładoznawczych to transkrypcja tekstu wyjściowego [np. Ivanova 1999; Englund Dimitrova i Tiselius 2009, 2014] czy nagranie tekstu docelowego w formacie audio [np. Bartłomiejczyk 2006; Gumul 2012, 2017, 2020] lub wideo [Russell i Winston 2014; Díaz Galaz 2018]. Nieliczni badacze łączą oba te bodźce [Vik-Tuovinen 2002; Tang 2018]. Każde z tych rozwiązań ma swoje minusy. Sama transkrypcja tekstu wyjściowego może okazać się niewystarczającym bodźcem słabo stymulującym pamięć, natomiast nagrania tekstu docelowego mogą

$5 \quad$ Kwestia ta została szerzej omówiona w pracy Gumul [2019]. 
prowokować komentarze, które są obserwacjami poczynionymi post factum i które nie odzwierciedlają świadomie podjętych decyzji podczas procesu tłumaczenia ${ }^{6}$. Z kolei łączenie transkrypcji i nagrania tekstu docelowego mogą stanowić nadmiar bodźców i działać rozpraszająco na badanych thumaczy. Podobnie ma się rzecz z wideonagraniami. Dylak [1996] w swojej pracy z dziedziny glottodydaktyki przytacza krytykę tej metody przestawioną przez Yingera [1986]:

[r]ejestracja wideo zawiera o wiele więcej zdarzeń-bodźców niż rejestracja audio, gdzie nauczyciel bardziej może polegać na swojej pamięci. Wideorejestracja, na skutek zawierania wielkiej liczby bodźców, może być bardziej rozpraszająca niż rejestracja tylko dźwiękowa. Poza tym odtwarzana rejestracja wideo zawiera o wiele więcej sygnałów niż podmiot mógł zaobserwować kiedy był w sytuacji rzeczywistej. To wszystko może współprzyczyniać się do kreowania w pamięci epizodycznej zdarzenia na ekranie, różniącego się od zdarzenia oryginalnego [Dylak 1996: 80].

Ten ostatni argument, związany z kreowaniem w pamięci epizodycznej zdarzeń, jest często przytaczany przez wielu badaczy również jako inherentny mankament użycia bodźców stymulujących pamięć badanych, bez względu na jego rodzaj. Każdy z nich niesie za sobą ryzyko wystąpienia fałszywych wspomnień (ang. installing false memories). Mechanizm ich występowania jest związany z funkcjonowaniem pamięci generatywnej, która uruchamia skrypt danej sytuacji [Olszewska 2007]. W ten sposób tłumaczowi może się wydawać, że pamięta zachowania, które są typowe dla pewnych sytuacji thumaczeniowych, a które tym razem wcale nie miały miejsca [zob. Gumul 2019].

Bodźcem stymulującym pamięć tłumacza mogą też być pytania zadawane przez badacza. W wielu pracach na temat metodologii badań przekładu [m.in. Kalina 1998, cyt. za: Bartłomiejczyk 2007a; zob. także Bartłomiejczyk 2006; Gumul 2017] podkreśla się, że udział badacza w samej retrospekcji powinien być minimalny i ograniczać się do wydania niezbędnych instrukcji przed rozpoczęciem sesji po to, aby nie zakłócać procesu retrospekcji i nie wpływać na werbalizacje tłumaczy [zob. Gumul 2019]. Jednak część badaczy decyduje się na formę wywiadu retrospektywnego

6 Ostatnie badania nad rolą bodźca w retrospekcji sugerują, że różnica między tymi dwoma rodzajami bodźca (transkrypcja tekstu wyjściowego i nagranie tłumaczenia), jeśli chodzi o wpływ na informacyjność werbalizacji, ich obfitość oraz dokładność, jest o wiele mniejsza, niż do tej pory uważano [Gumul 2020]. 
[Ivanova 2000; Napier 2002; Tang 2018; Díaz Galaz 2018]. Ta forma retrospekcji, określana też w polskiej literaturze przedmiotu mianem introspekcji kierowanej [Dylak 1996, za: Kruszewski 1988] (ang. stimulated recall), wzorowana jest często na badaniach glottodydaktycznych, jak w przypadku badań Díaz Galaz [2018], która opierała się pracy Gass i Mackey [2000/2009]. Jak podkreśla Witkowska [2010: 149], w glottodydaktyce rola badacza podczas sesji retrospektywnej jest zdecydowanie bardziej aktywna: jego zadaniem jest towarzyszyć badanemu i zachęcać go do werbalizacji, zadając dodatkowe pytania. $\mathrm{W}$ protokole czynności badacza zastosowanym przez Díaz Galaz [2018] widnieją pytania takie jak np.: „O czym myślałeś w tamtej chwili?”, „Zauważyłam, że zawahałeś się / że zmieniłeś pozycję. Dlaczego to zrobiłeś? O czym wtedy myślałeś?”, „Jak myślisz, dlaczego to zrobiłeś?”, „Dlaczego zawahałeś się, zanim odpowiedziałeś na pytanie?". Russell i Winston [2014] pytały także o to, czy badani byli zadowoleni ze swojego thumaczenia, o segmenty tekstu docelowego, które w odczuciu badanych tłumaczy nie były udane, oraz czy tłumaczenie wykonane na potrzeby badania było porównywalne z tym, jak zazwyczaj tłumaczą. Pytania zadawane thumaczom mogą także dotyczyć określonych rozwiązań tłumaczeniowych lub konkretnych segmentów tekstu. Przykładowo Tang [2018] prosiła tłumaczy o podanie powodów eksplicytacji, wskazując na segmenty tekstu, w których badana osoba wyraziła się bardziej eksplicytnie, niż miało to miejsce w oryginale. Ta forma retrospekcji może być jedyną metodą [np. Díaz Galaz 2018], jednak najczęściej badacze stosują ją jako narzędzie dodatkowe, niejako uzupełniające samodzielną retrospekcję thumaczy [Ivanova 2000; Napier 2002; Tang 2018].

Jednak ten wariant retrospekcji ma swoje minusy. Potencjalnie negatywny wpływ pytań badacza na wiarygodność uzyskanych w ten sposób raportów retrospektywnych podkreślają m.in. Ericsson i Simon [1980] i Ericsson [2003]. Twierdzą oni, iż dodatkowe pytania ze strony badacza raczej zmuszają badanych do wyciągania wniosków, niż stymulują ich pamięć. Często, by odpowiedzieć na pytanie, badani muszą uciekać się do spekulacji na temat powodów takiego, a nie innego rozwiązania [Ericsson 2003: 14]. W istocie procedura ta może sugerować badanym odpowiedzi. W badaniach translatorycznych thumacz może też czuć się zobligowany, by wyjaśnić powody w rzeczywistości odruchowego rozwiązania czy też w pełni zautomatyzowanej strategii, co może dać fałszywy obraz badanego zjawiska. $\mathrm{Z}$ tego powodu w badaniu opisywanym 
w artykule [Gumul 2017] każdy z tłumaczy słuchał w kabinie własnego tłumaczenia, dokonując jednocześnie samodzielnej retrospekcji.

\subsection{Transkrypcja i kodowanie protokotów retrospektywnych}

Transkrypcja uzyskanych w badaniu protokołów retrospektywnych jest niezwykle ważnym etapem badania, ponieważ to właśnie na jej podstawie dokonuje się na ogół analizy. Forma transkrypcji protokołów retrospektywnych zależy w dużej mierze od celu badania. W zależności od tego, jakie informacje są istotne dla analizy, badacze decydują się na dosłowną pełną transkrypcję lub naturalną transkrypcję. Ta pierwsza, określana przez Saldanhę i O'Brien [2013: 128] mianem denaturalised transcription, jest wiernym zapisem uwzględniającym wszystkie powtórzenia, wtrącenia, błędy, przejęzyczenia, urwane zdania oraz pauzy. $\mathrm{W}$ drugim wariancie, w tzw. naturalnej transkrypcji (naturalised transcription), zwanej też wygładzoną, usuwane są zbędne powtórzenia, przejęzyczenia i inne wspomniane wyżej cechy, jednak bez ingerencji w sens samej wypowiedzi. Zapis jest poprawny składniowo i gramatycznie. Nie zawiera też oznaczenia pauz. Dodaje się natomiast znaki interpunkcyjne i wyróżnia graficznie przytaczane w relacji fragmenty tekstu wyjściowego czy docelowego oraz słowa w innym języku niż język retrospekcji. Transkrypcja taka przypomina bardziej język pisany [ibidem: 128-129].

Takie rozwiązanie (naturalną transkrypcję) zastosowano w badaniach własnych autorki [Gumul 2017]. Jest ono widoczne w prawej kolumnie na przykładzie dwóch segmentów protokołu retrospektywnego jednego z uczestników badania (przykład 4). Lewa kolumna przedstawia pierwszą wersję uwzględniającą cechy dosłownej transkrypcji. Na pewnym etapie sporządzania zapisu protokołów uznano, że naturalna transkrypcja jest wystarczająca do analizy badanego zjawiska (w tym przypadku strategiczności eksplicytacji). Dosłowną pełną transkrypcję zastosowano natomiast w przypadku zapisu tekstu wyjściowego i tekstów docelowych (por. przykład $1 \mathrm{w}$ sekcji 1), jako że cechy parajęzykowe, takie jak np. pauzy czy zawahania, tworzą integralną część produktu w thumaczeniu symultanicznym (mogą być wyznacznikiem m.in. zwiększonego wysiłku kognitywnego). $\mathrm{Z}$ tego względu są bardzo istotne w analizie wszelkich zjawisk w tej formie przekładu. Inaczej rzecz ma się z protokołami retrospektywnymi, które nie są produktem przekładu, a jedynie relacją opisującą proces. W ich przypadku cechy parajęzykowe często nie wnoszą nic nowego do interpretacji opisywanych procesów. 
(4)

\begin{tabular}{|c|c|}
\hline $\begin{array}{l}\text { ugi raz } \\
\text { koś } \\
\text { to kalka } \\
\text { taka } \\
\text { ak to } \\
\text { zastoso- } \\
\text { ne słów- } \\
\text { rds }\end{array}$ & $\begin{array}{l}\text { P73/T4/RC7: Starałem się już drugi raz } \\
\text { pominąć słówko formulate bo jakoś } \\
\text { miałem wątpliwości czy nie jest to kalka } \\
\text { z języka polskiego i czy istnieje taka } \\
\text { kolokacja w języku angielskim, jak to: } \\
\text { formulate questions. Więc zastosowałem } \\
\text { takie bardziej neutralne słówko to put } \\
\text { something in other words. }\end{array}$ \\
\hline $\begin{array}{l}\text { ię nad } \\
\text { iczną } \\
\text { jedyne } \\
\text { wniczy } \\
\text { i posta- } \\
\text { miejscu } \\
\text { jest } \\
\text { m co jest }\end{array}$ & $\begin{array}{l}\text { P73/T4/RC14: Zastanawiałem się nad } \\
\text { jakąś logiczną kolokacją w języku } \\
\text { angielskim. Jedyne co przyszło mi } \\
\text { do głowy to prawniczy zwrot to be } \\
\text { reasonably justified i postanowiłem go } \\
\text { zastosować w tym miejscu, co myślę, } \\
\text { że spełnia swoją rolę i jest mniej więcej } \\
\text { synonimiczne z tym co jest w oryginale. }\end{array}$ \\
\hline $\begin{array}{l}\text { uż eee } \\
\text { rzed- } \\
\text { odzi ee } \\
\text { o czyli }\end{array}$ & $\begin{array}{l}\text { 23: Nie dodawałem juz zycia } \\
\text { onieważ z poprzedniego } \\
\text { wynikało, że chodzi o zagro- } \\
\text { horego, czyli albo życie albo }\end{array}$ \\
\hline
\end{tabular}

Należy jednak zaznaczyć, że niektórzy badacze rezygnują z wykonania transkrypcji protokołów. Na takie rozwiązanie zdecydowały się Shamy i de Pedro Ricoy [2017], argumentując to niemożnością oddania na poziomie zapisu graficznego takich cech jak ton głosu. Badaczki utrzymują, że na tej podstawie można potencjalnie określić, czy werbalizowany komentarz ma charakter czysto retrospekcyjny (czyli jest przywołaniem z pamięci procesów myślowych doświadczonych podczas tłumaczenia), czy też jest tylko interpretacją usłyszanego właśnie własnego tłumaczenia [ibidem: 59]. O ile cechy takie jak ton głosu niezaprzeczalnie mogą stanowić źródło dodatkowych informacji podczas analizy materiału, o tyle argument o możliwości dokonania rozróżnienia na tej podstawie pomiędzy komentarzami czysto retrospekcyjnymi a tymi inferowanymi na podstawie produktu wydaje się mało przekonujący. Na pewno warto włączyć do analizy również zapis audio [zob. także McLellan, MacQueen et al. 2003], jednak wykonanie transkrypcji znacznie ułatwia analizę i, jak podkreśla Niemants [2012: 175], pozwala badaczowi zapoznać się 
lepiej z materiałem. Saldanha i O'Brien [2013: 128] zwracają także uwagę na inną korzyść wypływającą z samego procesu transkrypcji. Na etapie przekształcania zapisu audio w zapis graficzny można wypracować bądź udoskonalić system kodowania protokołów, który jest kolejnym ważnym etapem przygotowania materiału do analizy?

System kodowania protokołów jest $\mathrm{w}$ dużej mierze uwarunkowany celem badania. Badacze oznaczają te cechy, które będą potrzebne na kolejnym etapie analizy. Jednak bez względu na cel badania pierwszym krokiem jest podział protokołu na komentarze odnoszące się do określonych segmentów tekstu. W opisywanym w niniejszym artykule badaniu zostały one oznaczone symbolem RC (od ang. retrospective comment) i kolejno numerami, począwszy od RC1 (odrębna numeracja dla protokołu każdego z uczestników). W tekście transkrypcji thumaczeń oznaczenia te pojawiają się jako numer przypisu (zob. przykład $1 \mathrm{w}$ sekcji 1). Każdy komentarz jest także oznaczony symbolem nadanym każdemu z biorących udział w badaniu thumaczy (od P01 do P120) oraz symbolem tekstu wyjściowego (od T1 do T6).

(5)

P90/T6/RC11: Niestety bardzo długo szukałam ekwiwalentu dla łatwego przecież słowa leki, przez co umknęło mi następne zdanie, a jeszcze kolejne zostało mocno skrócone. Zdecydowałam się na takie rozwiązanie, żeby zdążyć z kolejnym zdaniem.

Kolejny etap to oznaczanie protokołów pod kątem istotności. Jak podkreśla wielu badaczy [np. Ericsson i Simon 1984; Hansen 2005; Bartłomiejczyk 2006], protokoły retrospektywne charakteryzują się niską selektywnością i znaczna część komentarzy nie spełnia wymogów badania, a jako taka nie jest istotna dla analizy. Przykładowo, w pracy Bartłomiejczyk [2006] tylko połowa uzyskanych przez nią komentarzy opisywała działanie strategiczne thumaczy. Podobny problem wystąpił w badaniu opisywanym w artykule Gumul [2017]. Aż 1072 z 5005 komentarzy nie

\footnotetext{
7 Badacz nie jest oczywiście zobligowany do samodzielnego wykonywania transkrypcji. Zadanie to można zlecić np. firmie świadczącej tego typu usługi. Niektóre projekty badawcze zakładają taki rodzaj współpracy. W sukurs tłumaczowi mogą przyjść także coraz bardziej popularne i z roku na rok coraz bardziej udoskonalane programy do transkrypcji automatycznej oraz edycji transkrypcji - np. narzędzia używane w projekcie CLARIN [zob. https://clarin.phonetik.uni-muenchen.de/BASWebServices/interface oraz Pömp i Draxler 2017].
} 
dotyczyło decyzji świadomie podjętych podczas thumaczenia. Do tej grupy należały m.in. uwagi dotyczące jakości przekładu, komentarze opisujące odczucia badanych osób oraz komentarze otwarcie potwierdzające ich nieretrospektywny charakter, w których pojawiały się takie określenia jak np. „Nie wiem, dlaczego tak powiedziałam”. Wszystkie komentarze uznane za nieistotne zostały oznaczone symbolem IrC (od ang. irrelevant retrospective comment):

(6)

P88/T5/IrC3: W całym tym akapicie zostało przekazanych mało treści. Spowodowane było to prawdopodobnie niedosłyszeniem i stresem.

P88/T5/IrC7: Generalizacja. Nie wiem, czy słuszna.

P07/T1/IrC12: Nie jestem zadowolona z thumaczenia tego fragmentu.

Na ostatnim etapie protokoły kodowane są w zależności od analizowanego zjawiska. Ericsson i Simon [1999: 204], wykorzystujący tę metodę na potrzeby badań psychologicznych, podkreślają, że kodowanie zjawisk dotyczących procesów nie powinno odbywać się tylko na podstawie samych raportów retrospektywnych, ale także z uwzględnieniem uzyskanych danych. W przypadku badań translatorycznych dane te będzie stanowić tekst tłumaczenia. Mowa tu po raz kolejny o konieczności triangulacji metod badawczych. Przy kodowaniu komentarzy retrospektywnych konieczne jest zatem odniesienie do samego produktu przekładu. Ekstremalnym przykładem na kodowanie protokołów na podstawie zapisu tekstu docelowego jest praca Tang [2018], w której badaczka koduje raporty werbalne, niejednokrotnie przypisując im inne motywacje niż te deklarowane przez tłumaczy, opierając się głównie na wyznacznikach tekstowych.

W opisywanym w artykule badaniu [Gumul 2017], którego celem była analiza eksplicytacji, oznaczono najpierw w tekstach docelowych wszystkie przykłady tej transformacji tekstowej, a następnie w przypad$\mathrm{ku}$ tych zwerbalizowanych $\mathrm{w}$ protokołach retrospektywnych opatrzono odpowiednim kodem każdy z komentarzy. Kodowanie obejmowało dwa poziomy: formę eksplicytacji (np. reiterację [Reit], dookreślenie leksykalne $[\mathrm{LxSp}]^{8}$, leksykalizację form pronominalnych $[\mathrm{LxPF}]^{9}$, uzupełnianie

\footnotetext{
[LxSp] - skrót od ang. lexical specification.

[LxPF] - skrót od ang. lexicalisation of proforms.
} 
konstrukcji eliptycznych [FElli ${ }^{10}$ ) oraz powód eksplicytacji (ograniczenia tłumaczenia symultanicznego [Cnstr $]^{11}$, poprawianie tekstu $[\operatorname{ImpT}]^{12}$, pomoc odbiorcy $[\mathrm{HpR}]^{13}$, unikanie dwu/wieloznaczności $\left.[\mathrm{AvA}]^{14}\right)$.

(7)

P44/T4/RC13: Powtórzenie słówka spowodowane potrzebą wydłużenia czasu skonstruowania zdania. [Reit] [Cnstr]

P67/T3/RC2: Pacjenci - słowo to jest dokładniejsze niż słowo ludzie, lecz wydało mi się lepsze w kontekście tekstu o medycynie. [LxSp] [ImpT]

P46/T3/RC7: Tutaj natomiast wyraziłam się bardziej eksplicytnie, ponieważ them z tekstu wyjściowego zamieniłam na lekarzy, dla lepszego zrozumienia tekstu u odbiorcy. [LxPF] [HpR]

P61/T4/RC2: Zamiast użyć krótkiego Nie, nie może, przypomniałam czego lekarz nie może, dla rozwiania wątpliwości, o co chodzi. [FElli] [AvA]

Jak wynika z powyższego opisu, kodowanie w przypadku badań nad jednym zjawiskiem jest dość proste. Jednak, w zależności od celu badania, system kodowania może być bardzo złożony. Tak jest w przypadku badania Ivanovej [1999] na temat przetwarzania tekstu w thumaczeniu symultanicznym, w którym system kodowania protokołów retrospektywnych obejmuje 4 główne kategorie i ponad 20 podkategorii. Ivanova koduje werbalizacje tłumaczy, dzieląc je na problemy z przetwarzaniem (np. niemożność nadążenia za mówcą), uwagi na temat monitorowania własnego przekładu (np. emocjonalna ocena własnego przekładu), strategie (np. redukcja tekstu) oraz makrostrategie (np. komentarze dotyczące cech tekstu wyjściowego) ${ }^{15}$.

Z powyższego przeglądu literatury wynika, że kodowanie danych znacznie różni się w zależności od potrzeb danego badania. Jak podkreśla Englund Dimitrova [2005: 82], w translatoryce nie istnieją ustalone procedury kodowania werbalizacji introspektywnych i każdy badacz dostosowuje system kodowania do potrzeb własnej analizy i celu badania.

\footnotetext{
$10 \quad$ [FElli] - skrót od ang. filling out ellipsis.

11 [Cnstr] - skrót od ang. constraints.

12 [ImpT] - skrót od ang. improving the text.

13 [HpR] - skrót od ang. helping the reader.

14 [AvA] - skrót od ang. avoiding ambiguity.

15 System kodowania zastosowany w pracy doktorskiej Ivanovej został także szczegółowo przedstawiony w artykule Englund Dimitrovej i Tiselius [2009: 131-134].
} 


\section{Podsumowanie}

Wszystkie omówione w artykule składowe badania są jego istotnymi elementami. Jak widać, badacz ma do dyspozycji szereg różnorodnych rozwiązań. Decyzja, które rozwiązania przyjąć, zależy w dużej mierze od rodzaju i celu badania. Należy jednak pamiętać, że każde z nich rodzi określone konsekwencje i ma znaczny wpływ na uzyskane dane. Projektując badanie z użyciem metody protokołów retrospektywnych, należy również pamiętać o ograniczeniach tej metody. Badacz opiera się na subiektywnych relacjach thumaczy, a nie na mierzalnym wyznaczniku danego zjawiska. Ponadto raporty tego rodzaju z natury rzeczy są zawsze niekompletne. Przyczyną są nie tylko ograniczenia pamięci badanych, ale także np. ich niechęć do podzielenia się z badaczem pewnymi informacjami. Również możliwości zweryfikowania prawdziwości werbalizacji są dość ograniczone ${ }^{16}$. Nie zmienia to jednak faktu, że protokoły retrospektywne są doskonałym źródłem informacji na temat procesu przekładu. Tym cenniejszym, że ujawniają, jak ten proces wygląda z perspektywy samego tłumacza.

\section{Bibliografia}

Bartłomiejczyk, M. (2006), „Strategies of simultaneous interpreting and directionality", Interpreting. 8(2): 149-174, https://doi.org/10.1075/intp.8.2.03bar.

Bartłomiejczyk, M. (2007a), „Introspective methods in conference interpreting research", [w:] Janusz Arabski, red. Challenging Tasks for Psycholinguistics in the New Century. Proceedings of the 7th Congress of International Society of Applied Psycholinguistics (CD), Wydawnictwo Uniwersytetu Śląskiego, Katowice.

Bartłomiejczyk, M. (2007b), „Interpreting quality as perceived by trainee interpreters: Self-evaluation", The Interpreter and Translator Trainer 1(2): 247267, https://doi.org/10.1080/1750399X.2007.10798760.

Brzeziński, J. (2008), Badania eksperymentalne w psychologii i pedagogice, Wydawnictwo Naukowe Scholar, Warszawa.

Brzeziński, J., Stachowski, R. (1984), Zastosowanie analizy wariancji w eksperymentalnych badaniach psychologicznych, PWN, Warszawa.

16 Problematyka ograniczeń metody została szczegółowo omówiona w pracy Gumul [2019]. 
CLARIN, [online] https://clarin.phonetik.uni-muenchen.de/BASWebServices/ interface, 25.01.2019.

Creswell, J. W. (2013), Projektowanie badań naukowych. Metody jakościowe, ilościowe i mieszane (tłum. Joanna Gilewicz), Wydawnictwo Uniwersytetu Jagiellońskiego, Kraków.

Díaz Galaz, S. (2018), „A stimulated recall study on comprehension strategies for interpreting: implications for interpreter training", referat wygłoszony na konferencji didTRAD PACTE, Barcelona 20-23 czerwca 2018.

Dylak, S. (1996), „Nauczycielska samoobserwacja dla rozumienia «siebie»”, Neodidagmata. 22: 73-85.

Englund Dimitrova, B. (2005), Expertise and Explicitation in the Translation Process, John Benjamins Publishing Company, Amsterdam-Philadelphia, https://doi.org/10.1075/btl.64.

Englund Dimitrova B., Tiselius, E. (2009), „Exploring retrospection as a research method for studying the translation process and the interpreting process", [w:] Inger M. Mees, Fabio Alves, Susanne Göpferich, red. Methodology, Technology and Innovation in Translation Process Research, Samfundslitteratur, Copenhagen, 109-134.

Englund Dimitrova B., Tiselius E. (2014), „Retrospection in interpreting and translation: Explaining the process?", Monti. 1: 177-200, https://doi. org/10.6035/MonTI.2014.ne1.5.

Ericsson, K. A. (2003), „Valid and non-reactive verbalization of thoughts during performance of tasks. Towards a solution to the central problems of introspection as a source of scientific data", Journal of Consciousness Studies. 10(9-10): 1-18, https://doi.org/10.1037/0033-295X.87.3.215.

Ericsson, K. A., Simon, H. A. (1980), „Verbal reports as data”, Psychological Review. 87(3): 215-251, https://doi.org/10.1037/0033-295X.87.3.215.

Ericsson, K. A., Simon, H. A. (1984), Protocol Analysis: Verbal Reports as Data, MIT Press, Cambridge, MA.

Ericsson, K. A., Simon, H. A. (1993), Protocol Analysis: Verbal Reports as Data, wyd. 2, MIT Press, Cambridge, MA, https://doi.org/10.7551/ mitpress/5657.001.0001.

Ferreira, A. (2014), „Analyzing recursiveness patterns and retrospective protocols of professional translators in L1 and L2 translation tasks", Translation and Interpreting Studies. 9(1): 109-127, https://doi.org/10.1075/tis.9.1.06fer.

Gass, S. M., Mackey, A. (2000/2009), Stimulated Recall Methodology in Second Language Research, Lawrence Erlbaum Associates, Mahwah, NJ. 
Gumul, E. (2012), „Tłumacz o ograniczeniach. Z uwag retrospektywnych thumaczy symultanicznych", [w:] Przemysław Janikowski, red. $Z$ zagadnień $d y-$ daktyki thumaczenia ustnego 2. Stare problemy, nowe metody, Wydawnictwo Wyższej Szkoły Lingwistycznej, Częstochowa, 91-116.

Gumul, E. (2017), Explicitation in Simultaneous Interpreting. A Study into Explicitating Behaviour of Trainee Interpreters, Wydawnictwo Uniwersytetu Śląskiego, Katowice.

Gumul, E. (2019), „O metodzie protokołów retrospektywnych w badaniach nad thumaczeniem symultanicznym”, Rocznik Przekladoznawczy. 14, 171-192, https://doi.org/10.12775/RP.2019.008.

Gumul, E. (2020), „Retrospective protocols in simultaneous interpreting - testing the effect of retrieval cues", Linguistica Antverpiensia. New Series - Themes in Translation Studies. 19: 152-171.

Hansen, G. (2005), „Experience and emotion in empirical translation research with think-aloud and retrospection", Meta. 50(2): 511-521, https://doi. org/10.7202/010997ar.

Hild, A. (2007), „Establishing rigour in a between-method investigation of SI expertise", [w:] Yves Gambier, Miriam Shlesinger, Radegundis Stolze, red. Doubts and Directions in Translation Studies, John Benjamins Publishing Company, Amsterdam-Philadelphia, 99-112, https://doi.org/10.1075/ btl.72.12hil.

Hild, A. (2015), „Retrospective protocols”, [w:] Franz Pöchhacker, red. Routledge Encyclopedia of Interpreting Studies, Routledge, London, 351-353.

Ivanova, A. (1999), Discourse Processing During Simultaneous Interpreting: An Expertise Approach. Niepublikowana praca doktorska, University of Cambridge, Cambridge.

Ivanova, A. (2000), „The use of retrospection in research on simultaneous interpreting", [w:] Sonja Tirkkonen-Condit, Riitta Jääskeläinen, red. Tapping and Mapping the Processes of Translation and Interpreting: Outlooks on Empirical Research, John Benjamins Publishing Company, Amsterdam-Philadelphia, 27-52.

Kalina, S. (1998), Strategische Prozesse beim Dolmetschen: theoretische Grundlagen, empirische Fallstudien, didaktische Konsequenzen, Gunter Narr, Tübingen.

Kruszewski, K. (1988), Kształcenie w szkole wyższej, PWN, Warszawa.

Liu, M. (2011), „Methodology in interpreting studies: A methodological review of evidence-based research", [w:] Brenda Nicodemus, Laurie Swabey, red. Advances in Interpreting Research: Inquiry in Action, John 
Benjamins Publishing Company, Amsterdam-Philadelphia, 85-119, https:// doi.org/10.1075/btl.99.08liu.

Liu, M. (2015), „Experimental research”, [w:] Franz Pöchhacker, red. Routledge Encyclopedia of Interpreting Studies, Routledge, London, 150-151.

McLellan, E., MacQueen, K., Neidig, J. (2003), „Beyond the qualitative interview: Data preparation and transcription", Field Methods. 15(1): 63-84, https://doi.org/10.1177/1525822X02239573.

Napier, J. (2002), Sign Language Interpreting: Linguistic Coping Strategies, Douglas McLean, Coleford, UK.

Niemants, N. (2012), ,The transcription of interpreting data”, Interpreting. 14(2): 165-191, https://doi.org/10.1075/intp.14.2.03nie.

Olszewska, J. (2007), „Wiedza i wyobraźnia a zjawisko fałszywej pamięci”, Roczniki psychologiczne. 10(2): 75-88.

Pömp, J., Draxler, C. (2017), „OCTRA - a Configurable Browser-Based Editor for Orthographic Transcription", [w:] Proceedings of Phonetik und Phonologie im deutschsprachigen Raum, Leibniz-Center for General Linguistics, Berlin, 145-148.

Russell, D., Winston, B. (2014), „Tapping into the interpreting process: Using participant reports to inform the interpreting process in educational settings", Translation \& Interpreting. 6(1): 102-127, https://doi.org/10.12807/ ti.106201.2014.a06.

Saldanha, G., O'Brien, S. (2013), Research Methodologies in Translation Studies, Routledge, London-New York, https://doi.org/10.4324/9781315760100.

Shamy, M., de Pedro Ricoy, R. (2017), „Retrospective protocols: Tapping into the minds of interpreting trainees", Translation \& Interpreting. 9(1): 51-71, https://doi.org/10.12807/ti.109201.2017.a05.

Tang, F. (2018), Explicitation in Consecutive Interpreting, John Benjamins Publishing Company, Amsterdam-Philadelphia, https://doi.org/10.1075/btl.135.

Tiselius, E., Jenset, G. B. (2011), „Process and product in simultaneous interpreting: What they tell us about experience and expertise", [w:] Cecilia Alvstad, Adelina Hild, Elisabet Tiselius, red. Methods and Strategies of Process Research: Integrative Approaches in Translation Studies, John Benjamins Publishing Company, Amsterdam-Philadelphia, 269-300, https://doi.org/10.1075/ bt1.94.20tis.

Vik-Tuovinen, G.-V. (2002), „Retrospection as a method of studying the process of simultaneous interpreting", [w:] Giuliana Garzone, Maurizio Viezzi, red. Interpreting in the 21st Century: Challenges and Opportunities, John 
Benjamins Publishing Company, Amsterdam-Philadelphia, 63-71, https:// doi.org/10.1075/btl.43.07vik.

Witkowska, M. (2010), „Zastosowanie protokołu głośnego myślenia i retrospekcji w badaniach autorefleksji przyszłych nauczycieli języka angielskiego", Neofilolog. 34: 147-157, https://doi.org/10.14746/n.2010.34.13.

Yinger, R. J. (1986), „Examining thought in action: A theoretical and methodological critique of research on interactive teaching", Teaching and Teacher Education. 2(3): 263-282, https://doi.org/10.1016/S0742-051X(86)80007-5.

\section{STRESZCZENIE}

Celem artykułu jest omówienie poszczególnych etapów badania przeprowadzonego z użyciem metody protokołów retrospektywnych w badaniach nad tłumaczeniem symultanicznym na przykładzie badań własnych autorki. Omówione zostały takie aspekty jak projektowanie badania z uwzględnieniem triangulacji tej metody z innymi narzędziami badawczymi, dobór uczestników badania, sposoby instruowania i przygotowania badanych do zadania, jak również kwestia wyboru bodźca stymulującego pamięć. Zaprezentowano także metody transkrypcji oraz kodowania protokołów retrospektywnych.

Słowa kluczowe: protokoły retrospektywne, tłumaczenie symultaniczne, metody badawcze, triangulacja, transkrypcja, kodowanie

\section{Abstract \\ The Method of Retrospective Protocols in Translation and Interpret- ing Studies}

The aim of the article is to discuss the stages of research conducted adopting the method of retrospective protocols in simultaneous interpreting research. The discussion is based on the author's own research. The presentation begins with possible research designs usually involving triangulation with other methods. The author also discusses the problem of participants selection, instructions and training provided before the task, the choice of cuing stimuli, and finally transcription and coding conventions.

Keywords: retrospective protocols, simultaneous interpreting, research methods, triangulation, transcription, coding 